Si Dionisio lo dice, o no? Sancti Spiritus y el acto de toma de posesión del territorio

\title{
Si Dionisio lo dice, o no? Sancti Spiritus y el acto de toma de posesión del territorio
}

\section{If Dionysius says so, or not! Sancti Spiritus and the act of taking possession of the territory}

\author{
Iban Sánchez-Pinto \\ Departamento de Geografía, \\ Prehistoria y Arqueología, \\ Grupo de Investigación en Patrimonio Construido; \\ Universidad del País Vasco/Euskal Herriko Unibertsitatea (España) \\ iban.sanchez@ehu.eus.es \\ Museo Etnográfico y Colonial Juan de Garay, \\ Ministerio de Cultura de la Provincia de Santa Fe (Argentina) \\ gabrielcocco@gmail.com
}

\section{Resumen}

La proximidad del V centenario de la construcción del asentamiento de Sancti Spiritus, ha hecho necesaria una reflexión en torno a la efeméride del arribo de Sebastián Gaboto a la confluencia de los ríos Carcarañá y Paraná y la toma de posesión del territorio. Esta revisión ha culminado en la propuesta de una nueva data sobre el momento del arribo de la expedición y la construcción del asentamiento.

\section{Palabras Clave}

Caboto; fundación; asentamiento; Espíritu Santo; Domingo de Resurrección.

\section{Abstract}

The proximity of the V centenary of the construction of the Sancti Spiritus settlement has made it necessary to reflect on the anniversary of the arrival of Sebastian Gaboto at the confluence of the Carcaraña and Parana rivers and the taking of possession of the territory. This review has culminated in the proposal of a new date for the arrival of the expedition and the construction of the settlement.

\section{Keywords}

Caboto; foundation; settlement; Holy Spirit; Easter Sunday. 


\section{Iban Sánchez-Pinto y Gabriel Cocco}

\section{Introducción}

Hace más de una década que comenzó un proyecto muy ambicioso impulsado por el gobierno de la provincia de Santa Fe y cuya continuidad a día de hoy se mantiene a pesar de los vaivenes institucionales. El proyecto titulado "Investigación científica en el sitio histórico de Puerto Gaboto: localización del primer asentamiento español en el Río de la Plata" tenía entonces, y ahora, como misión principal encontrar evidencias culturales del asentamiento de Sancti Spiritus construido por la expedición española que capitaneaba Sebastián Caboto, por entonces piloto Mayor de la Casa de Contratación de Sevilla (Medina, 1908a; Frittegotto et al., 2013; Cocco et al., 2016). Los trabajos de investigación iniciados en el año 2006 han dado como fruto, después de más de una veintena de campañas de excavación y de una meticulosa revisión de la documentación escrita, la localización del lugar exacto al que llegó la expedición en la confluencia del río Carcarañá con el Coronda tal y como, por otra parte, refiere la documentación escrita de la época y los cronistas de Indias (Medina, 1908a; Fernández de Oviedo, 1959; Castañeda, Cuesta, \& Hernández, 1983; Cuesta Domingo, 2016).

A lo largo de todos estos años la temática abordada en relación a la expedición ha tratado diferentes temas relativos a la materialidad del asentamiento (Cocco, \& Letieri, 2009; Bonomo et al., 2012; Frittegotto et al., 2013; Azkarate, Escribano-Ruiz, Sánchez-Pinto, \& Benedet, 2016; Cocco et al., 2016; Azkarate, Escribano-Ruiz, Sánchez-Pinto, \& Benedet, 2018), la cultura material (Pasquali, 2012; Pasquali, \& Escribano-Ruiz, 2013; Letieri et al., 2015a; Letieri \& Cocco, 2015), el viaje (Medina, 1908a; Astiz, \& Tomé, 1987; Azkarate, Sanchez-Pinto, Escribano-Ruiz, \& Benedet, 2014) e, incluso, a los aspectos sociales derivados del propio proceso de investigación y su difusión a la comunidad (Frittegotto et al., 2013; Benzi, 2013). Sin embargo, en estos últimos años, no se ha prestado atención a la data del arribo de la expedición a la confluencia de los ríos Carcarañá con el Paraná y la construcción del asentamiento, tal vez, porque se daban por buenos los postulados previos o, porque al no señalarse expresamente, se consideró un tema menor. La creencia generalizada, que sitúa la data de la fundación en el 9 de junio de 1527, es la misma que sirvió para que en 1998 se institucionalizara, como parte del calendario de celebraciones oficiales de la provincia de Santa Fe, el Día de los Municipios, Comunas y Pueblos de la Provincia de Santa Fe como parte del calendario de celebraciones oficiales de la provincia, realizándose un acto multitudinario con tal motivo en la plaza 25 de Mayo de la actual localidad de Puerto Gaboto.

Una reciente relectura de la documentación emanada del proceso seguido a Caboto a su regreso a España, sin embargo, nos puso sobre la pista para poder proponer una nueva hipótesis de trabajo sobre la data del momento del arribo a la confluencia de los ríos Carcarañá y Coronda por parte de la expedición. Como veremos, una lectura cruzada de todo el volumen documental existente permite un acercamiento muy fiable al momento de construcción del asentamiento. No es nuestra intención, sin embargo, entrar a valorar la expedición de Sebastián Caboto ni las distintas vicisitudes de la misma, ya que existen abundantes referencias al respecto (Soler, 


\section{Si Dionisio lo dice, o no? Sancti Spiritus y el acto de toma de posesión del territorio}

1981, 1984, 1987; Cocco, \& Letieri, 2009; Frittegotto et al., 2013; Azkarate, Escribano-Ruiz, Sánchez-Pinto, \& Benedet, 2016; Cocco et al., 2016; Azkarate, Escribano-Ruiz, Sánchez-Pinto, \& Benedet, 2018; Medina, 1908a; Astiz, \& Tomé, 1987; Azkarate, Sanchez-Pinto, Escribano-Ruiz, \& Benedet, 2014; Báez, 1944; Capparelli, Lema, Giovannetti, \& Raffino, 2005; Colobig et al. 2017; Colobig, Zucol, Passeggi, Azkarate, \& Sánchez-Pinto, 2019; Azkarate, \& Escribano-Ruiz, 2015; Astiz, 2013). De cara a construir nuestros argumentos sí que prestaremos especial atención a alguno de los acontecimientos por los que atravesó la expedición a lo largo de su periplo, ya que son los que nos van a servir para ir acomodando los escasos datos con los que contamos y poder así establecer de forma fiable el momento de la construcción del asentamiento. Además, realizaremos una revisión del momento de fundación de algunas de las otras localidades llamadas Sancti Spiritus y conocidas como son las situadas en Salamanca (España), Badajoz (España) y Cuba, ya que pensamos que el cotejo de los datos que manejamos junto con la información que poseemos sobre estas tres localidades ayudarán a entender mejor aún nuestra hipótesis.

\section{Qué sabemos sobre la fecha de fundación de Sancti Spiritus}

\section{Datos derivados de la expedición}

Después de toda una serie de preparativos, la expedición encabezada por Sebastián Caboto partió el 3 de abril de 1526 desde el puerto de Sanlúcar de Barrameda con la finalidad de comerciar con el Maluco aprovechando la ruta abierta por la expedición de Magallanes/Elcano. Caboto no dudó en incumplir las capitulaciones que tenía firmadas con el Rey nada más partir del puerto, y cambiar la finalidad del viaje, para ir en busca de las riquezas que supuestamente había remontando el río Paraná. No queda claro, sin embargo, que infringiera las capitulaciones totalmente, ya que en las mismas se explicita que pueda rescatar en las islas y tierra firme ya descubiertas o por descubrir y, además, se dice de forma explícita que en los siguientes cuatro viajes, que deben realizarse en un máximo de 8 años, nadie pueda ir ni a las islas ni tierra firme "nuevamente descubierta" en el viaje, o en los sucesivos hasta completar los cuatro señalados (AGI/22.15.2582//INDIFERENTE, 2495, L.1). Este dato, no menor, pensamos que permitía a Caboto hacer lo que hizo, dado que se le dan importantes prerrogativas para los viajes futuros $y$, aunque de manera velada, se le faculta para explorar y rescatar en las tierras que vaya descubriendo, ya sean islas o tierra firme, y poder seguir haciéndolo durante los siguiente ocho años a su descubrimiento.

Sin entrar en mayores detalles sobre el viaje, ya analizado con anterioridad (Medina, 1908a; Azkarate, Sanchez-Pinto, Escribano-Ruiz, \& Benedet, 2014; Cocco et al., 2016), la expedición después de un largo viaje llega al cabo de Santa María (Figura 1. Actual Punta del Este, Uruguay) (Cuesta Domingo, 1984, T. II: 365) el 21 de febrero de 1527 (Maura, 2007) y comienza a remontarlo hasta llegar el 6 de abril de 1527, 
al lugar que llamaron Puerto de San Lázaro (Figura 1. En territorio uruguayo, según los investigadores que han realizado una aproximación a su posible ubicación se situaría de forma aproximada entre el río de San Juan y Nueva Palmira) (Madero, 1892; Medina, 1908a; Laguarda Trías, 1992; Maura, 2007; El Jaber, 2011; Tieffemberg, 2012). Después de permanecer un mes en este lugar, tiempo suficiente para reabastecerse, Caboto parte el día 8 de mayo de 1527 con dirección al que será el futuro asentamiento de Sancti Spiritus (Maura, 2007), dejando en San Lázaro a parte de los expedicionarios para que guardaran la hacienda y a Antón de Grajeda con el encargo de que buscara un puerto seguro para las dos naos que aún tenían y que se quedaban allí por no poder remontar el río Paraná (Medina, 1908a; Maura, 2007). El siguiente dato con el que contamos señala que Caboto mandó la galeota, para recoger la hacienda que había dejado en el real de San Lázaro y a la gente que había quedado en su guarda, llegando ésta el 14 de agosto de 1527 y partiendo el 28 del mismo mes en dirección al Carcarañá (Maura, 2007). Al llegar a Sancti Spiritus los expedicionarios que habían quedado en San Lázaro constatan la existencia ya que Caboto “...había hecho su asiento y una fortaleza arto fuerte... (Maura, 2007. El subrayado y la negrita es nuestro)”. Esta es la información directa más completa con la que contamos, por lo que cabe suponer que la construcción del asentamiento se realizó entre el 8 de mayo y el 14 de agosto de 1527, sin poder afinar más los datos por el momento.

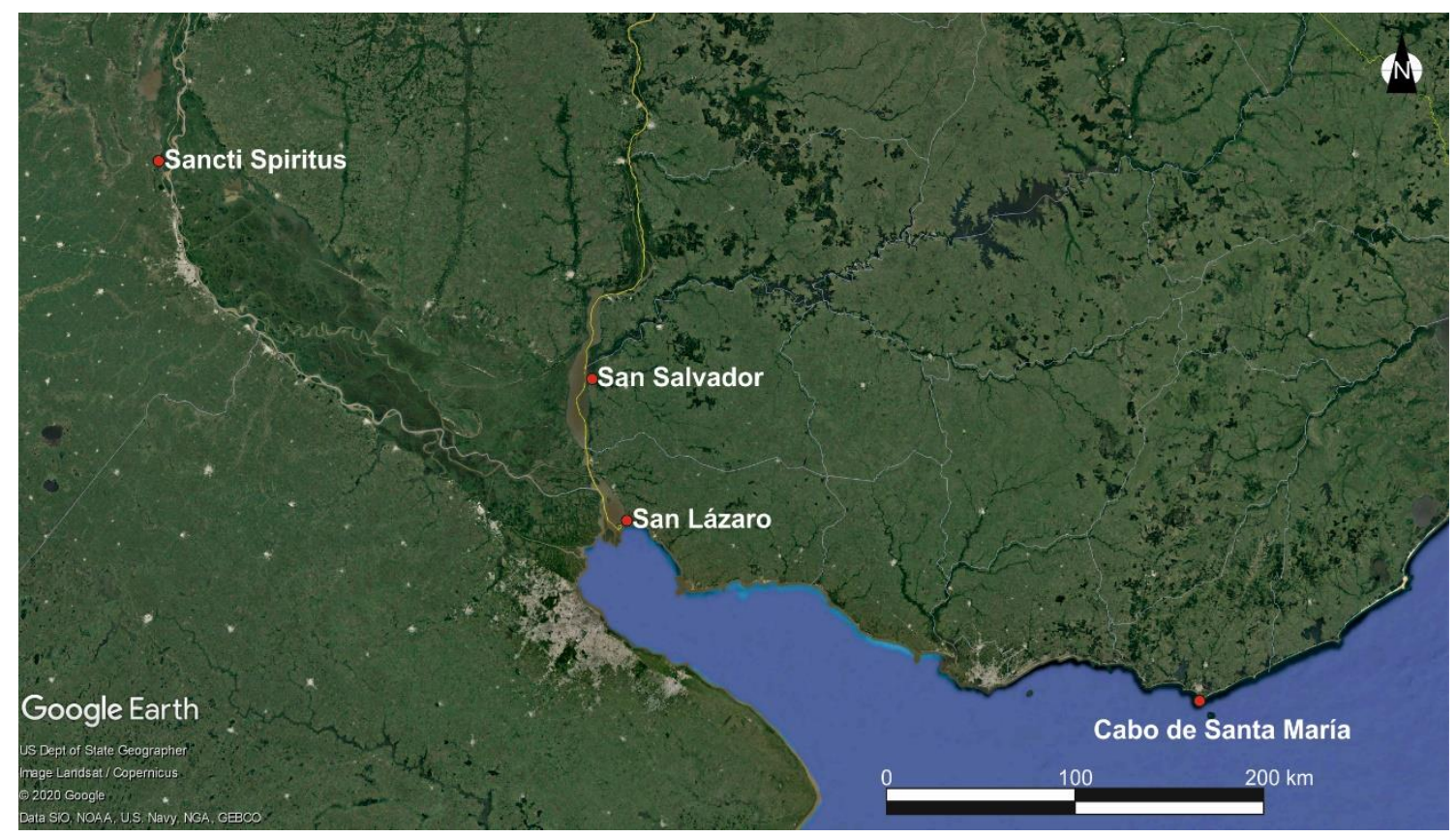

Figura 1. Situación de los principales enclaves en los que se detuvo la expedición una vez llegó al río de la Plata (Imagen: elaboración propia a partir de Google Earth). 


\section{Si Dionisio lo dice, o no? Sancti Spiritus y el acto de toma de posesión del territorio}

Poco más se puede señalar en relación a los datos directos aportados por la documentación de la época, siendo las dos datas extremas señaladas una primera aproximación al problema.

\section{Datos posteriores}

Los principales cronistas de indias del siglo XVI (Francisco López de Gómara, Fernández de Oviedo, Herrera y Tordesillas) (Fernández de Oviedo, 1959; Castañeda, Cuesta, \& Hernández, 1983; Cuesta Domingo, 2016), los integrantes de la expedición de Caboto que realizaron meritorias publicaciones R. Barlow y Santa Cruz (Cuesta Domingo, 1983; Taylor, 1932), Diego García de Moguer (Medina, 1908b), quien coincidió con la expedición de Caboto en el río Paraná, e incluso Richar Eden, con quien Caboto compartió muchos de los aspectos de su viaje a su regreso a Inglaterra (Arber, 1885), nada indican en relación a la data de fundación del asentamiento señalando, en el mejor de los casos, su ubicación en el río Carcarañá. Tendremos que esperar bastante para contar con las primeras propuestas sobre la data de construcción del asentamiento. El padre Lozano, quien sigue los datos aportados por Ruy Díaz de Guzmán, tampoco señala ninguna noticia en relación a la fecha de construcción del asentamiento (Lozano, 1875; Tieffemberg, 2012).

Uno de los primeros autores que se hace eco de la data en la que Caboto llega a la confluencia de los ríos Carcarañá y Coronda es Madero (1892) quien señala que esta efeméride se corresponde con el 27 de mayo. Desconocemos en base a qué propone esta fecha, ya que en todo momento se guía por la carta de Luis Ramírez (Maura, 2007) y algunos de los documentos emanados de la expedición que pudo consultar pero que, como hemos señalado, nada dicen al respecto. Con anterioridad son varios los autores que se refieren a la expedición de Sebastián Caboto y narran diferentes aspectos de la misma, sin embargo, no aportan referencias que permitan avanzar en la cuestión que estamos tratando (Azara, 1847).

H. Harrisse quien en 1896 publicara una de las obras monumentales sobre John y Sebastián Caboto, tampoco hace alusión alguna a la data de construcción del asentamiento, a pesar de referir importantes datos (Harrisse, 1896). Motivado por sus intereses personales en los primeros asentamientos establecidos a lo largo de la primera mitad del siglo XVI en territorio argentino, Félix F. Outes publicó una noticia histórico-geográfica sobre Sancti Spiritus y señala que la fecha en que la expedición llega la desembocadura del río Carcarañá es el 27 de mayo de 1527 (Outes, 1902). Si bien no lo señala el autor, está recogiendo la información vertida con anterioridad por Madero a la que ya nos hemos referido. Con posterioridad a Harrisse y Outes verán la luz las obras de José Toribio Medina (1908a), junto a la de Harrisse la mejor relación de la vida y obras de Sebastián Caboto, y la obra de Manuel M. Cervera (1908) sobre la historia de la ciudad y provincia de Santa Fe. Medina no duda en señalar que se llamó al fuerte Sancti Spiritus por haber llegado al Carcarañá el 19 de mayo fecha en la que, según el autor, se celebró en 1527 el día de Pentecostés; 
Cervera, por su parte, señala que Caboto llegó a la confluencia de los ríos Carcarañá y Coronda el 27 de mayo, siguiendo claramente a Madero, si bien el autor no da mayores indicaciones.

Si bien Medina ya introduce la noción de la fiesta de Pentecostés, no señala nada más en relación a la misma. Será P. Groussac (1916) quien, al referirse a la expedición de Caboto, y la fecha en la que llegó a la confluencia de los ríos Coronda/Carcarañá, indica que Pentecostés no es una fiesta fija y que su fecha se establece siete semanas después de la Pascua de resurrección. Para el autor, por tanto, en 1527 el día de Pentecostés cayó el 9 de junio, siendo el primero de los autores que hemos podido consultar que señalan tal data. Sin embargo, Groussac, no nos provee de los cálculos de los que se vale para realizar tal aserto.

Enrique de Gandía $(1929,1934)$ al referirse a Sancti Spiritus y el momento de su construcción, señala el 9 de junio como la fecha en la que se produjo, siguiendo en este sentido lo señalado con anterioridad por Groussac. Unos pocos años más tarde Julián Ma Rubio (1942) escribe que Caboto le puso al asentamiento Sancti Spiritus por haber llegado en esa festividad y que en 1527 se correspondió con el día 11 de mayo. Canals Frau (1948) al tratar de reconstruir el periplo de la entrada de Francisco César, integrante de la expedición de Sebastián Caboto quien remontando por tierra el río Carcarañá y se introdujo en el interior del territorio en busca de la sierra de la plata, señala que la fecha de fundación del asentamiento de Sancti Spiritus se produjo el 9 de junio, si bien no especifica de dónde o cómo ha alcanzado dicha data, cabe suponer que sigue a Groussac/Gandía.

En 1978 Luis A. Ledesma Medina retoma la misma data aportada por Groussac para señalar que la fecha de construcción del asentamiento debió de ser el 9 de junio de 1527.

Amadeo Soler $(1981,1984,1987)$ no duda, al igual que Groussac o Gandía, en señalar el 9 de junio como la data en la que se estableció el asentamiento sobre las barrancas del Carcarañá. Muy probablemente el erudito gabotense siguió al insigne historiador Enrique de Gandía, ya que en su obra "Sebastián Gaboto. El primer argentino, 1984" no duda en señalar que tanto él como Gandía han dado cuidada mención a este aspecto.

Ya en pleno siglo XXI Guillaume Candela $(2007 / 2008)$ en su memoria de máster no duda en señalar como la data de construcción del asentamiento el 11 de mayo de 1527, si bien el autor señala que ésta la obtiene de la obra de Rubio (1942). Finalmente, Ricardo N. González (2014) profesor de historia y gran conocedor de la historia de Puerto Gaboto, afirma que la instalación del asentamiento de Sancti Spiritus queda terminada el 9 de junio de 1527, tal y como el historiador José María Rosa (1970) señala. Al igual que Groussac (1916) señala que la celebración de Pentecostés es una solemnidad "movible" que se celebra entre el 20 de mayo y el 9 de junio de cada año y que no se fija en relación al calendario civil y, como el fuerte se empezó a construir en este lapso de tiempo, 20 de mayo a 9 de junio, y se finalizó el 9 de junio es el motivo por el que se le puso el nombre relacionado con la fiesta del Espíritu Santo (Pentecostés). 


\section{Si Dionisio lo dice, o no? Sancti Spiritus y el acto de toma de posesión del territorio}

\begin{tabular}{|l|l|l|l|}
\hline \multicolumn{1}{|c|}{ Año } & \multicolumn{1}{|c|}{ Autor } & Fecha propuesta & A quién sigue? \\
\hline 1892 & Madero & 27 de mayo & \\
\hline 1902 & Outes & 27 de mayo & Madero \\
\hline 1908 & Medina & 19 de mayo & \\
\hline 1908 & Cervera & 27 de mayo & Madero \\
\hline 1916 & Groussac & 9 de junio & \\
\hline 1929,1934 & Gandía & 9 de junio & Groussac \\
\hline 1942 & Rubio & 11 de mayo & \\
\hline 1948 & Canals Frau & 9 de junio & Groussac \\
\hline 1978 & Ledesma Medina & 9 de junio & Groussac \\
\hline $1981,1984,1987$ & Soler & 9 de junio & Gandía \\
\hline $2007 / 2008$ & Candela & 11 de mayo & Rubio \\
\hline 2014 & González & 9 de junio & Soler, Rosa \\
\hline
\end{tabular}

Tabla 1. Tabla resumen con los autores citados

Además de estos autores, existen otros que señalan la posible data de construcción del asentamiento, aunque ninguno de ellos amplia las fechas apuntadas con anterioridad (Palacios, 2018). Los estudios más recientes sobre Sancti Spiritus se limitan a señalar el 9 de junio de 1527 como fecha probable (Astiz \& Tomé, 1987) o, directamente, el 9 de junio de 1527 (Frittegotto et al., 2013; Benzi, 2013). En una reciente publicación nosotros mismos señalamos que el asentamiento se construyó entre mayo y agosto de 1527, sin poder precisar mucho más la data (Colobig et al., 2017).

\section{El día de Pentecostés. ¿Cómo se establece?}

Hemos visto como algunos autores ya señalan, de forma acertada, que la celebración de Pentecostés, Espíritu Santo, es una fiesta móvil no ligada al calendario civil. Es P. Groussac (1916) uno de los primeros autores que lo dice e indica que la celebración de Pentecostés no es un día fijo del calendario, siendo su celebración siete semanas después de la Pascua de resurrección o Domingo de Resurrección. Medina (1908a) se limita a señalar que el día de Pentecostés en 1527 se celebró el 19 de mayo de 1527, lo que invita a pensar que el autor era consciente de esta variabilidad, si bien no llega a señalarlo. Hoy sabemos que la celebración de Pentecostés, Espíritu Santo (Sancti Spiritu), es una fiesta móvil que se celebra 50 días después del Domingo de Resurrección. 


\begin{tabular}{|l|l|l|l|l|l|l|}
\hline Lunes & Martes & Miércoles & Jueves & Viernes & Sábado & $\begin{array}{l}\text { Día 1. Domingo de } \\
\text { Resurrección }\end{array}$ \\
\hline Día 2 & Día 3 & Día 4 & Día 5 & Día 6 & Día 7 & $\begin{array}{l}\text { Segundo domingo de } \\
\text { Pascua }\end{array}$ \\
\hline Día 9 & Día 10 & Día 11 & Día 12 & Día 13 & Día 14 & Tercer domingo de Pascua \\
\hline Día 16 & Día 17 & Día 18 & Día 19 & Día 20 & Día 21 & Cuarto domingo de Pascua \\
\hline Día 23 & Día 24 & Día 25 & Día 26 & Día 27 & Día 28 & Quinto domingo de Pascua \\
\hline Día 30 & Día 31 & Día 32 & Día 33 & Día 34 & Día 35 & Sexto domingo de Pascua \\
\hline Día 37 & Día 38 & Día 39 & Día 40 & Día 41 & Día 42 & $\begin{array}{l}\text { Séptimo domingo de } \\
\text { Pascua }\end{array}$ \\
\hline Día 44 & Día 45 & Día 46 & Día 47 & Día 48 & Día 49 & Día 50. Pentecostés \\
\hline
\end{tabular}

Tabla 2. Tabla con la representación de cómo se calcula el día de Pentecostés

No parece, por tanto, difícil de establecer la fórmula mediante la que se puede calcular cuándo fue el día de Pentecostés en cualquier fecha. Para poder establecer el día de Pentecostés, debemos conocer primero cuando fue el día de Pascua, ya que es a partir de esta data que se calculan todas las demás fiestas movibles del calendario cristiano. Este cálculo quedó instaurado por Dionisio el Exiguo ya en el siglo VI d. C., si bien su uso no se generalizó hasta la centuria siguiente en España, y es lo que se conoce como Computus paschalis (Jones, 1943; García Avilés, 2001; Morales, 2017). Hasta la celebración de los concilios de Arlés (314 d.C.) y Nicea (324 d. C.), la celebración de la Pascua se basaba en el calendario lunar exclusivamente, lo que suponía que ésta se celebrara en el plenilunio contiguo al equinoccio de primavera. Poco a poco, desde Roma, se comenzó a imponer el que la Pascua se celebrara en domingo, frente a la celebración judía (García Avilés, 2001). Será el concilio de Nicea donde se establezcan ya las bases para el cálculo de la Pascua, si bien no soluciona el problema del uso de los calendarios de Roma y Alejandría, los más empleados entonces. La diferencia del empleo de uno u otro radicaba en la fecha en la que se situaba el equinoccio de primavera, al ser el 25 de marzo para los romanos y el 21 de marzo para los alejandrinos, con lo que existían desacuerdos sobre el primer y último día en el que el domingo de Pascua podía caer (García Avilés, 2001). Es por ello que, finalmente, en el propio concilio de Nicea se adoptó el cómputo alejandrino, si bien aún existieron períodos con serias discrepancias al respecto (García Avilés, 2001).

Habrá que esperar a que Dionisio "el Exiguo" (†556), quien introdujo la era cristiana como referencia para elaborar el cómputo, elabore sus tablas para calcular la Pascua que abarcan el período del 532 al 626 d.C. (Teres, 1984; Gómez Pallarés, 1999). La importancia de Dionisio, sin embargo, en los cálculos pascuales va mucho más allá de la elaboración de esta tabla, ya que el autor dejó asentados los argumenta paschalia. En efecto, Dionisio dejó establecidas las fórmulas de cálculo eclesiástico 


\section{Si Dionisio lo dice, o no? Sancti Spiritus y el acto de toma de posesión del territorio}

mediante las cuales los clérigos podían calcular las fechas móviles de la celebración pascual después de que sus tablas dejarán de tener utilidad (Jones, 1943; Gómez Pallarés, 1999). Si bien en el concilio de Nicea ya se fijaron algunas normas que se debían cumplir de cara al establecimiento del día de Pascua, será Dionisio quien los deje definitivamente establecidos (Thurston, 1909; Morales, 2017). Así:

a) La Pascua ha de caer en domingo.

b) Este domingo deber ser el siguiente a la primera luna llena después del equinoccio de primavera. Aunque si esa fecha cae en domingo, se traslada al domingo siguiente para no coincidir con la Pascua judía.

c) La luna pascual es la que cumple que su plenilunio se produce en el equinoccio de primavera del hemisferio norte o inmediatamente después. Dicho equinoccio es el 21 de marzo.

d) Se necesita saber el día del ciclo lunar en el que está la Luna el 1 de enero del año del que queremos hacer el cálculo. Este dato oscilará entre el 0 y el 29.

Atendiendo a estas premisas, el día de Domingo de Resurrección tiene que caer entre el 22 de marzo y el 25 de abril. Para hacer el cálculo del año deseado actualmente se emplea el algoritmo de Gauss, si bien existen otros métodos a partir de los que se pueden calcular, como es el algoritmo de Butcher (1877), por ejemplo, si bien este último método es válido para cualquier fecha posterior a 1583. A pesar de la existencia de tablas de duración determinada, la fecha se solía calcular a través de los argumenta, bien fueran los de Dionisio o de cualquier otro monje (Plaza Picón, \& González Marrero, 2005).

Siguiendo lo expuesto por Morales (2017) para calcular el Domingo de Resurrección, llamaremos A al año del cual lo queremos calcular y estableceremos 10 variables para buscar la fecha dentro de ese año: $a, b, c, p, q, M, N, d$ y $e$, que se estructuran tal y como se observa en la imagen siguiente.

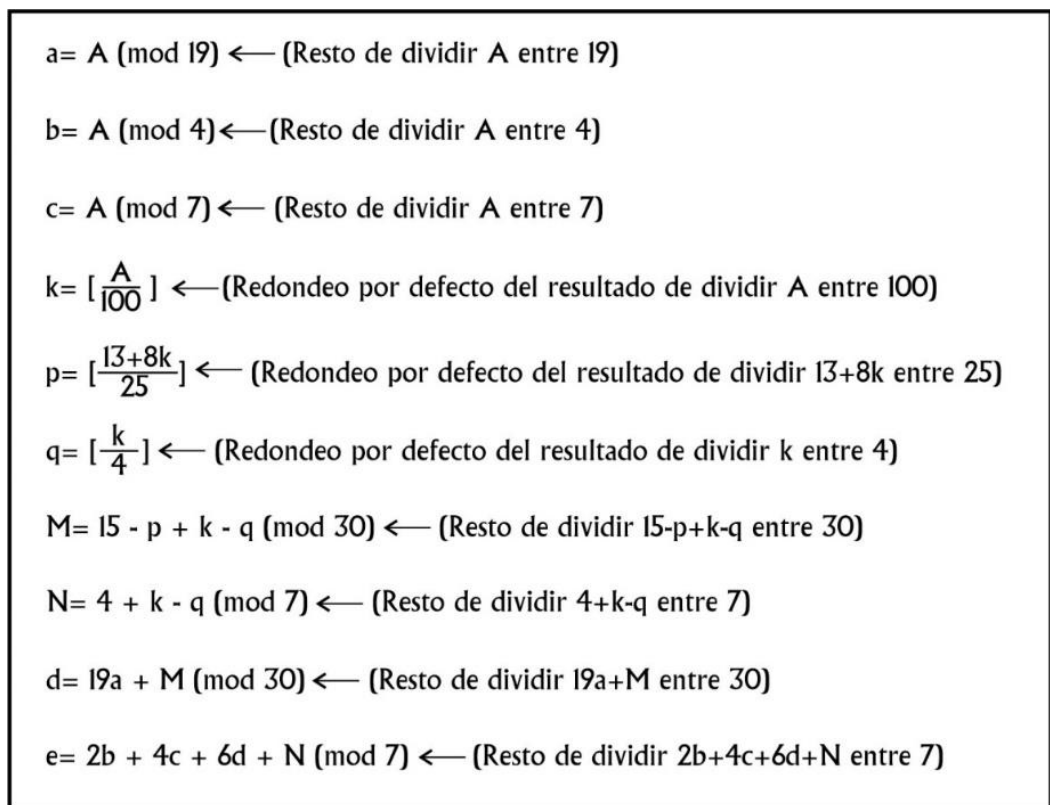

Figura 2. Imagen con la definición de las variables de Gauss (elaboración propia a partir de Morales, 2017) 
A partir de la determinación de estas variables la fecha del Domingo de Resurrección puede articularse en dos momentos que vienen determinados por:

Si $d+$ e $<10$, el Domingo de Resurrección es el día d + e+ 22 de marzo

Si d + e > 9, el Domingo de Resurrección es el día d + e+ 9 de abril

A esta norma existen dos excepciones. Si la data resultante es el 26 de abril, el Domingo de Resurrección será el 19 de abril y, si el resultado es el 25 de abril con d= 28, e= 6 y a $>10$, el Domingo de Resurrección será el 18 de abril.

Ya hemos determinado, por tanto, a partir de los postulados de Dionisio el exiguo la fórmula por la que se establece el Domingo de Resurrección, fecha clave a partir de la cual se calculan muchas de las fiestas cristianas. Veamos qué implicaciones tiene para el caso que estamos analizando, aunque previamente trataremos cómo se conforman el resto de Sancti Spiritus conocidos y qué significaba la toma de posesión de un territorio frente a una fundación propiamente dicha.

\section{Los otros Sancti Spiritus}

El nombre Sancti Spiritus se empleó en el medievo para designar tanto a localidades como a diferentes centros monásticos, muy conocidos son los monasterios de Ávila, fundado en 1171 (Moreno Blanco, 2016), Toro (Pérez Vidal, 2008), fundado en 1307, o el de Salamanca, fundado en 1268, (Villar y Macías, 1887; Echániz Sans, 1993), pequeñas iglesias que se situaban en los distintos núcleos de población como es el caso de la de Sancti Spiritus en Huesca (siglo XIII) que debe su nombre muy probablemente por haber pertencido a la Orden Hospitalaria de los Canónigos Regulares del Sancti Spiritus in Saxa (Alagón Castán, 2017) o, simplemente, calles de los diferentes municipios, como es la actual ronda de Sancti Spiritus en Salamanca (Villar y Macías, 1887) e, incluso, universidades como la de Oñati (Estornés Zubizarreta, 2020). Es, por tanto, un nombre conocido y empleado de forma profusa en época medieval, máxime cuando muchos de los nombres que se empleaban partían del santoral cristiano. Su uso, además, no tenía que coincidir con la fecha en la cual cayó el Corpus en cada uno de los años en que se fundaron los monasterios o se nombraron las calles o parajes.

Entre las localidades más relevantes que conocemos y que han llegado hasta nuestros días se encuentran las de Salamanca y Badajoz en España y la de Cuba. En las líneas que siguen trataremos de hacer una pequeña reseña de las mismas con los pocos datos que sobre sus fundaciones conocemos.

La pequeña villa de Sancti-Spiritus situada en la provincia de Salamanca, surgió al amparo del proceso de repoblación del norte peninsular de la mano de los monarcas leoneses a lo largo de la segunda mitad del siglo XII y siempre bajo la tutela de la vecina Ciudad Rodrigo, de la que era dependiente (Mínguez, 1997). Desde su constitución contó con el onomástico latino, si bien desconocemos cuál pudo ser la motivación del mismo, por lo que no podemos realizar mayores afirmaciones al no 


\section{Si Dionisio lo dice, o no? Sancti Spiritus y el acto de toma de posesión del territorio}

existir fecha de fundación o relato en el que apoyarnos. En la cercana villa de Salamanca, fundada a finales del siglo XI, se erigió una puebla, denominada de Sancti Spiritus, que parece fue poblada por gente venida de Zamora, ya que la advocación de la iglesia, Sancti Spiritus, tiene un origen zamorano (González, 1943), por lo que podemos entender que el nombre se trata de una traslación del mismo. Sin embargo, la puebla como tal, no adquiere el nombre de la parroquia hasta mediados del siglo XIII (Echániz Sans, 1992).

La villa de Sancti Spiritus situada en la provincia de Badajoz, conoce un proceso fundacional similar al de su homónima salmantina, si bien sus orígenes son algo más complejos. No será hasta comienzos dl siglo XIII que el territorio en el cual se emplazará la futura villa se reconquiste por parte de los castellanos. El nombre de la localidad se debe a un clérigo que durante un tiempo vio como una paloma se posaba sobre un olivo con la intención, supuestamente, de llamar su atención. Será en este lugar donde el religioso edifique un oratorio, que más tarde dio lugar a la iglesia parroquial, y la llamo del Espiritu Santo (Sancti Spiritu) al ser la paloma su símbolo (Castaño Fernández, 1998; Mora Aliseda, 2001). El topónimo de la localidad, como tal, se encuentra registrado en la documentación escrita desde el siglo XVI. Vemos, por tanto, que el nombre de la localidad, derivado de aquel primitivo oratorio, no se encuentra relacionado con la data en que cayera el día del Espiritu Santo en el año de su fundación, sino con la advocación de un oratorio, y posteriormente parroquia, a partir de la que se edificó la población.

La localidad de Sancti-Spiritus, en Cuba, fue fundada por Diego Velázquez de Cuellar en 1514. No existe, sin embargo, un consenso sobre la fecha exacta de su fundación, tendiéndose a señalar como tal el 4 de junio, día de Pentecostés en 1514, aunque también se señala el mes de marzo como posible fecha para su constitución. Prieto Benavent (2001), en una magnífica biografía de Diego Velázquez de Cuellar, se limita a señalar el año 1514 como data de la construcción, pero sin avanzar mucho más en ello. Lorenzo (1985) en su semblanza sobre Diego Velázquez como colonizador de la isla de La Española, nada señala en relación a data de fundación de la ciudad. En sendos estudios a cargo de Irene Aloha Wright (1916) y Florstedt (1942) en relación a la historia de Cuba y la figura de Diego Velázquez, los autores señalan que Sancti Spiritus está fundado ya para el verano de 1514, sin aportar data concreta alguna a pesar de haber manejado un importante volumen documental de la época. Algo similar dice Rodríguez Matamoros (2013), quien al dar cuenta de los trabajos arqueológicos desarrollados en el sitio fundacional de la villa del Espíritu Santo señala que fue fundada a principios de 1514. Bartolomé de las Casas, quien estuvo junto con Diego de Velázquez, escribe que estando éste en el pueblo de Baracoa señaló una serie de puntos que debían ser poblados: villa de la Trinidad, Sancti Spiritus, puerto Príncipe villa de San Salvador y en el puerto de Santiago (Saint-Lu, 1986: 125). El autor, gran conocedor de los hechos y que aporta fechas concretas en todo momento, nada señala en relación a estas fundaciones al situarlas en algún momento entre 1511 y 1514. Es más, de las Casas se mofa de Diego de Velázquez al 


\section{Iban Sánchez-Pinto y Gabriel Cocco}

señalar, en relación a la villa de la Trinidad, “...como si la Santísima Trinidad hubiera de ser allí servida...” (Saint-Lu, 1986: 125).

Vemos, por tanto, que en los casos señalados el empleo del nombre Sancti Spiritus no necesariamente tiene que coincidir con la celebración de la festividad, sino que más bien responde al carácter simbólico de la misma a través de las manifestaciones que la representan. En este sentido un dato no menor, o eso creemos, es precisamente la representación del Espíritu Santo, el simbolismo asociado al empleo del nombre, ya que no en todos los casos su uso es necesariamente concordante con la data en la que se celebra. Tal y como hemos señalado, la paloma, es una de las representaciones simbólicas del Espíritu Santo, dado que se presentó en el bautismo de Jesús. Pero, junto a esta manifestación, existen otras muchas como son la mano, el sello, la nube y la luz, el fuego, la unción y el agua (mediante el sacramento del Bautismo. El agua representa el Espíritu otorgando un nuevo nacimiento) (Espíritu Santo, 2020).

Estas acepciones, que en el siglo XVI no debieron de ser extrañas, pueden también aportar una nueva lógica al nombre empleado por Sebastián Caboto. El poblado que construyó se situó en el cruce de dos vías de agua que desde época prehispánica actuaban como verdaderos ejes de comunicación y articulación del territorio. Así, el empleo del nombre Sancti Spiritus en un lugar preeminente del territorio parece dotar al emplazamiento de un nuevo resurgir, no debemos olvidar que Sancti Spiritus se construye directamente sobre un asentamiento originario (Letieri et al., $2015 b$ ), pero ahora ya bajo la autoridad de los expedicionarios recién arribados al territorio.

\section{¿Toma de posesión, fundación o asentamiento efímero en Sancti Spiritus?}

Un aspecto sobre el asentamiento de Santi Spiritus no debidamente analizado es sobre su propia naturaleza. Como muy bien señalaba Calvo (2017) Sancti Spiritus no fue una fundación como tal al carecer de mandamiento o capitulación para tal fin, no hubo asignación de jurisdicción y tampoco se llegó a configurar el territorio, al no tener Sebastián Gaboto tales poderes. El proceso de fundación de una ciudad constaba de dos pasos bien diferenciados como eran la toma de posesión del territorio en primer lugar y la posterior fundación mediante los actos que ello conllevaba (Domínguez Company, 1977; Michieli, 1996; Calvo 2003). Sin embargo, la primera, no necesariamente implica la segunda. Hay ejemplos de tomas de posesión que no terminan en un acto de fundación, como son el puerto de Nuestra Señora del Rosario, Puerto Bermejo o Estrecho de la Madre de Dios entre 1579 y 1580 (Domínguez Company, 1977: 23; Díaz, 2000). Es más, tal y como señala Gutiérrez (1983) muchas ciudades nacieron sin acta de fundación, sin cabildo, rollo o reparto de solares; muchas de ellas, además, carecieron de una traza inicial. Son ciudades cuyo culmen es el resultado de un complejo proceso evolutivo a partir de un núcleo generador. Asunción puede ser un buen exponente de este ejemplo, ya que, de un pequeño núcleo poblacional a partir de una casa fuerte, dio lugar con el 


\section{Si Dionisio lo dice, o no? Sancti Spiritus y el acto de toma de posesión del territorio}

paso del tiempo a una ciudad. Santa Fe la Vieja, si bien en un momento inicial cabría entrar dentro de este grupo de ciudades, es producto de un contexto histórico diferente, ya que la intencionalidad con la que surge está marcada por la estrategia de conquista basada en la fundación de ciudades planificadas. A pesar de ello, estas ciudades planificadas no surgen desde el primer momento con su traza debidamente establecida. Si atendemos a la comisión dada a Juan de Garay se dice que “...vaya a poblar e fundar el dicho puerto e pueblo (...) que lleven muchas armas y municiones, caballos, bastimentos, ganados, plantas, çemillas, gente de servicio, fragua (...) edificando iglesia e segundariamente casa fuerte en que puedan morar hasta hazer casas particulares..." (Groussac, 1915: 47-51). Dicho fuerte, tal y como refiere Calvo (2003) se llegó a construir y fue después que se trazó la ciudad. Si bien en Santa Fe sí que hubo un acto de fundación, vemos que el núcleo original, si bien solo de manera inicial, se constriñó a una iglesia y una casa fuerte, para posteriormente efectuar el trazado de la ciudad. Algo similar cabe señalar para el primer núcleo poblacional de Asunción (Gandía, 1932; Lafuente Machaín, 1936, 1939, 2004; Amarilla Fretes, 1942) o la primera Buenas Aires (Groussac, 1916; Schavelzon 1999, 2001, 2012; Candela, 2014), que aunque no llegó a prosperar tuvo una fundación efectiva. Buena prueba de lo que señalamos lo resume de manera magistral Michieli (1996), y el caso de Sancti Spiritus o Asunción son fiel reflejo, al referirse a las fundaciones de las ciudades de Cuyo y señalar que los primeros asentamientos se trataban de iniciativas personales o, en el mejor de los casos, de pequeños grupos con el fin de satisfacer necesidades concretas, si bien todas ellas tenían un mismo común denominador como era la toma de posesión y la posterior acta de fundación, este proceso no necesariamente partía de un mandamiento institucional.

Calvo (2003), a partir de la obra de Bernardo de Vargas Machuca "Milicias y descripción de las Indias (1599)", define de manera muy clara cuál es el proceso de fundación de una ciudad, qué pasos se deben dar, para considerarse como tal. Estos pasos consistían en: la colocación de un tronco de árbol, el rollo o picota, en un lugar señalado libre de cualquier rama. Este elemento simbolizaba el poder real y el lugar donde se impartiría justicia. Después de su colocación los asistentes se abrían en círculo entorno al fundador, que estaba junto al rollo donde clavaba un cuchillo, se giraba hacia los asistentes y gritaba que ese sitio señalaba la horca o picota y que allí dejaba fundada la ciudad, cuyo nombre entonces proclamaba públicamente. El ritual no acababa así, seguido el fundador blandía la espada y señalaba que de esta manera quedaba fundada la ciudad y retaba a quien se opusiera a batirse en duelo con él. El fundador repetía tres veces ese reto y los presentes respondían gritando: «La ciudad está bien poblada. ¡Viva el Rey Nuestro Señor!». La toma de posesión se completaba cuando el fundador cortaba hierbas y plantas con su espada, indicando simultáneamente la jurisdicción de la Audiencia o gobernación a la que pertenecería la ciudad. Cumplidos estos actos, se plantaba una cruz en una esquina de la plaza y se celebraba la misa con asistencia de todos los soldados (Vargas Machuca, 1599; Calvo 2003). 
De Sancti Spiritus, sin embargo, no se conservan apenas documentos generados en el lapso de tiempo que duró la expedición más allá de los que R. Barlow y compañía trajeron a la península en su viaje de regreso en 1528 y los que se redactaron con posterioridad a la expedición, ya que la destrucción del fuerte supuso también el que los documentos que allí estaban se quemaran. Es por ello que carecemos de datos efectivos sobre la toma de posesión del territorio o sobre un hipotético acto de fundación, que creemos nunca se llegó a realizar, ya que de existir hubiera quedado algún tipo de dato escrito o se hubiera señalado en alguno de los testimonios posteriores. Ya hemos señalado como en muchos casos la construcción de ciudades son fruto de iniciativas personales (Michieli, 1996), carentes del mandato real, que se consolidan con el tiempo. La única seguridad con la que contamos son las órdenes dadas en la capitulación donde se estipula que las tierras o islas nuevas descubiertas por Caboto quedarán bajo su jurisdicción para poder rescatar en las mismas en los próximos tres viajes a realizarse durante los siguientes ocho años (AGI/22.15.2582//INDIFERENTE,2495,L.1), lo que de alguna manera tuvo que tener algún tipo de refrendo para que Caboto pudiera reclamar la potestad sobre los territorios descubiertos con posterioridad. Ya hemos señalado que según Calvo (2018) Sancti Spiritus no fue una fundación como tal, y nosotros así lo creemos también. Sin embargo, a excepción de la capitulación, contó con el resto de elementos al estructurar el asentamiento en varios elementos: fortaleza, casas, tierras de labranza y puerto (Medina, 1908a; Sánchez-Pinto, Cocco, 2019), se realizaron repartimientos de tierra, a muy baja escala eso sí, existió una articulación del espacio en tres sectores que hemos denominado (Sánchez-Pinto, Cocco, 2019): área habitacional (casas y fortaleza), zona de producción (campos de cultivo) y puerto (en la margen izquierda del río Carcarañá). Además, sabemos que en una zona sobreelevada del territorio se colocó una cruz, símbolo de la apropiación del territorio, ligeramente retirada de la fortaleza en dirección norte ““....encima de la fortaleza (...) questaba buen rato de la fortaleza..." (Medina, 1908a, T. II). La expedición de Díaz de Solís cuando penetró en el estudio del Plata entraron en un puerto al que pusieron por nombre Nuestra Señora de la Candelaria (actual Maldonado, Uruguay). Cuando descendieron a tierra erigieron una cruz y tañendo las trompetas tomaron posesión para la corona de Castilla del lugar cortando árboles y ramas, ya que así eran las instrucciones que tenían de la corona (Madero, 1892; Medina, 1897). Vemos, por tanto, que la cruz además de simbolizar un lugar de cristianos es el elemento empleado para proceder a la toma de posesión del territorio, y es en este sentido que debemos entender la cruz que la expedición de Caboto colocó en el punto más alto de la confluencia de los ríos Carcarañá y Coronda.

\section{La documentación escrita, Dionisio el Exiguo y Sancti Spiritus}

Atendiendo a lo anteriormente expuesto, vemos que en Sancti Spiritus se realizó algo más que un simple campamento temporal, se llevaron a cabo acciones que, en otros ámbitos y circunstancias, hubieran sido tenidos en cuenta como elementos 


\section{Si Dionisio lo dice, o no? Sancti Spiritus y el acto de toma de posesión del territorio}

claramente observables en los inicios de las primeras ciudades. En este sentido, tal y como señala Domínguez Company (1977) muchas de las primeras ciudades americanas tienen como germen, porque así lo aconseja el propio proceso de conquista, un fuerte, una simple ranchería o un campamento. Pero la ocupación real del territorio se acompaña con el establecimiento de un poblado, y Sancti Spiritus lo es. En definitiva, la presencia de un asentamiento, del tamaño que sea, es la mayor garantía que se puede presentar frente al monarca a la hora de reclamar un territorio.

Ya hemos señalado qué sucede en otros establecimientos que tienen el mismo nombre que el poblado de Caboto. Para Sancti Spiritus contamos, además, con la base principal para establecer la data sobre el arrivo de la expedición a la confluencia de los ríos Carcarañá y Coronda y el establecimiento del poblado de Sancti Spiritus. Atendiendo a lo anteriormente expuesto no dudamos de que existió una toma de posesión del territorio efectiva, ya que era la manera en la que Sebastián Gaboto se garantizaba el poder reclamar frente al rey las cláusulas contenidas en la capitulación firmada entre ambos. Pero, volvamos a retomar los aspectos seguros con los que contamos de la expedición. Sabemos, porque así lo dice la documentación escrita, que los expedicionarios parten de San Lázaro el día 8 de mayo, con lo que la construcción del asentamiento, necesariamente, fue posterior. Una revisión de la importante documentación transcrita por Medina (1908a), aporta datos relevantes que no han sido considerados hasta la fecha pero que nos van a servir para establecer una primera data aproximada. Sebastián Caboto antes de volver a España realizó una probanza en el puerto de las naos de San Salvador (Figura 1. en la desembocadura del río San Salvador, cerca de la actual Dolores, Uruguay) el 12 de octubre de 1529 que constaba de hasta 35 preguntas, con cuestiones varias sobre la pérdida de la fortaleza y el papel de los que la defendían. Los integrantes de la expedición interrogados fueron Alonso de Santa Cruz, Maestre Pedro (cirujano), Francisco García (clérigo), Gaspar Cazaña, Jorge Gómez (lengua), Alonso de San Pedro, Alvaro Núñez (veedor de la nao Trinidad), Gregorio Caro (capitán de la nao Santa María), Juan de Junco (tesorero), Antonio de Montoya (contador) y Gómez Malaver. De todas las cuestiones planteadas, nos centraremos en la pregunta no 34 (Medina, 1908a. El subrayado y negrita es nuestro):

“...XXXIV.—ítem: pido que declaren si es verdad que luego que la dicha barca é capitán Caro é otra gente allegó á este puerto de las naos á donde estaba el dicho Capitán general, luego que el dicho Capitán general supo el daño que había hecho en la dicha fortaleza é de la gente que allí quedaba, luego se partió con cuatro bergantines, que se hallaban en este puerto, los dos desta armada é los otros dos del capitán Diego García, con el dicho capitán Diego García, para ir á la dicha fortaleza á socorrer la gente que allí quedaba, é en seis ó siete días allegaron á la dicha fortaleza é hallaron todos los cristianos muertos, dentro del Río de Caracaraná, en el agua é en la tierra, é la fortaleza robada é quemada; é visto todo lo suso dicho, el dicho Capitán general, que no tenía aparejo para tornar á rehacer la dicha fortaleza, por cabsa de mantenimientos para la gente, 
é que los indios comarcanos eran sus enemigos, é acordó de se volver á este puerto é naos, é así lo hizo, etc..."

De todos los interrogados solo Juan de Junco y Antonio Montoya remontaron el Paraná hasta la fortaleza. Sin embargo, todos ellos son rotundos a la hora de declarar al afirmar que las cosas sucedieron tal y como se dice en la pregunta, los que fueron porque lo vivieron y los que no porque se lo contaron.

Vemos, por tanto, que el cuestionario es claro. De San Salvador, puerto de las naos, hasta Sancti Spiritus se podía llegar en 6 o 7 días. Cabe suponer, por tanto, que desde San Lázaro, lugar del que en 1527 parte Sebastián Caboto, hasta la desembocadura del Carcarañá se podría llegar en un tiempo similar e incluso inferior al situarse más cerca de Sancti Spiritus. Según Alonso de Chaves (Castañeda, Cuesta, \& Hernández, 1983) la distancia entre San Lázaro y San Salvador era de 3 leguas que fácilmente eran navegables. Si sabemos que Caboto parte de San Lázaro el 8 de mayo, podría haber llegado perfectamente al Carcarañá el 14 o 15 de mayo. Tal y como hemos señalado, las tomas de posesión del territorio son inmediatas a que los expedicionarios llegan a los nuevos territorios y, según refiere la documentación escrita de la época (Medina, 1908a), Gaboto no se detuvo en ningún momento desde que partió de San Lázaro hasta que llegó al futuro emplazamiento de Sancti Spiritus, por lo que la información vertida en la probanza es un dato revelador en cuanto al tiempo que tardó en llegar la expedición.

Veamos ahora, aplicando la fórmula para el cálculo de la fiesta de Pascua, en qué día cayó en 1527 el Domingo de Resurrección y poder así calcular el día de Pentecostés.

$\mathrm{a}=$ resto de dividir 1527 entre $19=7$

$\mathrm{b}=$ resto de dividir 1527 entre $4=3$

$c=$ resto de dividir 1527 entre $7=1$

$\mathrm{k}=$ redondeo por defecto del resultado de dividir 1527 entre $100=15$

$\mathrm{p}=$ redondeo por defecto del resultado de dividir $13+8(15)$ dividido entre $25=5$

$\mathrm{q}=$ redondeo por defecto del resultado de dividir 15 entre $4=3$

$M=$ resto de dividir $15-5+15-3$ entre $30=2215$

Aquí es donde el uso de la fórmula plantea el primer error, y donde aparénteme no puede ser empleada, dado que M para el año 1527 es $15^{1}$ y no 22 como señala la fórmula. Existen tablas en las que se recoge el valor de $\mathrm{M}$, dado que se trata de un número que no varía demasiado en largos períodos de tiempo².

\footnotetext{
${ }^{1}$ Como albergábamos alguna duda sobre la utilidad de la fórmula para el año 1527, consultamos al archivo del Vaticano y el secretario del mismo nos comunicó que, según el diccionario de cronología de Cappelli (1930) el día de Pascua en 1527 cayó el 21 de abril.

2 https://www.catimenu.com/pascuat.htm consulta de 20/08/2020
} 


\section{Si Dionisio lo dice, o no? Sancti Spiritus y el acto de toma de posesión del territorio}

$\mathrm{N}=$ resto de dividir $4+15-3$ entre $7=z 6$

En este punto $\mathrm{N}$ arrastra el error de del cálculo de $\mathrm{M}$, por lo que el resultado no es 2 sino 6

$\mathrm{d}=$ resto de dividir $19(7)+22$ entre $30=528$

d, si calculamos la fórmula sin aplicar las correcciones anteriormente señaladas, tendía un valor de 5, pero con las correcciones da un valor de 28.

$\mathrm{e}=$ resto de dividir $2(3)+4(1)+6(5)+2$ entre $7=\theta 2$

Finalmente e no es igual a 0 , el valor correctl es 2 .

Como $d+e=30>10$, el Domingo de Resurrección es el día $\mathrm{d}+\mathrm{e}+9$. Por tanto, la Pascua en 1527 cayó el 21 de abril. Sabiendo que el 21 de abril de 1527 fue domingo, podemos calcular cuándo fue el día de Pentecostés. Recordemos que es el día 50 después de Pascua.

\begin{tabular}{|l|l|l|l|l|l|l|}
\hline Lunes & Martes & Miércoles & Jueves & Viernes & Sábado & $\begin{array}{l}\text { Día 21 de abril. } \\
\text { Domingo de } \\
\text { Resurrección }\end{array}$ \\
\hline 22 abril & 23 abril & 24 abril & 25 abril & 26 abril & 27 abril & $\begin{array}{l}28 \text { de abril. Segundo } \\
\text { domingo de Pascua }\end{array}$ \\
\hline 29 abril & 30 abril & 1 mayo & 2 mayo & 3 mayo & 4 mayo & $\begin{array}{l}5 \text { de mayo. Tercer } \\
\text { domingo de Pascua }\end{array}$ \\
\hline 6 mayo & 7 mayo & $8^{3}$ mayo & 9 mayo & 10 mayo & 11 mayo & $\begin{array}{l}12 \text { de mayo. Cuarto } \\
\text { domingo de Pascua }\end{array}$ \\
\hline $\begin{array}{l}13 \\
\text { mayo }\end{array}$ & 14 mayo & 15 mayo & 16 mayo & 17 mayo & 18 mayo & $\begin{array}{l}19 \text { de mayo. Quinto } \\
\text { domingo de Pascua }\end{array}$ \\
\hline $\begin{array}{l}20 \\
\text { mayo }\end{array}$ & 21 mayo & 22 mayo & 23 mayo & 24 mayo & 25 mayo & $\begin{array}{l}26 \text { de mayo. Sexto } \\
\text { domingo de Pascua }\end{array}$ \\
\hline $\begin{array}{l}27 \\
\text { mayo }\end{array}$ & 28 mayo & 29 mayo & 30 mayo & 31 mayo & 1 junio & $\begin{array}{l}2 \text { de junio. Séptimo } \\
\text { domingo de Pascua }\end{array}$ \\
\hline 3 junio & 4 junio & 5 junio & 6 junio & 7 junio & 8 junio & $\begin{array}{l}\mathbf{9} \text { de junio. } \\
\text { Pentecostés }\end{array}$ \\
\hline
\end{tabular}

Tabla 3. Tabla con el cálculo del día de Pentecostés en 1527 a partir de la fecha obtenida para el Domingo de Resurrección con las debidas correcciones aplicadas a la fórmula de Gauss.

A partir de los datos expuestos, vemos que existe una contradicción entre las declaraciones de los expedicionarios y la fecha sobre la que pudieron llegar a la confluencia del río Carcarañá con el Coronda y el día de Pentecostés en 1527. A partir de la documentación escrita es posible señalar que los expedicionarios llegaron a la confluencia de ambos ríos a mediados del mes de mayo de 1527 (entre

\footnotetext{
${ }^{3}$ Hay un dato muy interesante al que tampoco le habíamos prestado especial atención hasta la fecha. Maura (2007) al hacer el estudio de la carta de Luis Ramírez señala que en el manuscrito original pone que el 8 de mayo fue domingo, pero que se encuentra tachado y que en el momento de hacer la transcripción es ilegible el nuevo día. Medina (1908a) señala que el 8 de mayo fue viernes, tal vez el autor sí que llegó a verlo. En la edición que hace Jiménez de la Espada de la carta para Madero también se dice que es viernes (Madero, 1892).
} 
el 14-15) mientras que el día de Pentecostés en 1527 se celebró el 9 de junio. Por tanto, existe un conflicto entre la fecha derivada de la información documental generada por la propia expedición y el día real de la celebración del Espíritu Santo en 1527. Es en este punto donde creemos que toma especial relevancia el resto de aspectos señalados con anterioridad sobre el resto de fundaciones llamadas Sancti Spiritus y los elementos simbólicos asociados al Espíritu Santo.

Las referencias tanto a los Sancti Spiritus situados en España como al de Cuba, así como al resto de Santi Spiritus a los que nos hemos referido, no parece aludir en la mayoría de los casos a la efeméride en la que se celebra el día de Pentecostés, sino que más bien parecen responder al carácter simbólico con el que cuenta el Espíritus Santo. Así la aparición de una paloma, la presencia de agua revitalizadora o la aparición de un rayo de luz a través de una nube pueden ser motivos suficientes para señalar un lugar como Sancti Spiritus. No debemos olvidar, en este sentido, las palabras de fray Bartolomé de las Casas en relación a la villa de la Trinidad que funda Diego Velázquez de Cuellar. Las diferentes representaciones del Espíritu Santo son, en muchos casos, el verdadero vehículo empleado para nombrar tanto a las localidades, como a los edificios, barrios o diferentes puntos estratégicos en el relieve. Así tanto la paloma, como el resto de representaciones señalas, son motivo suficiente para nombrar. Creemos, sin embargo, que en caso de Sancti Spiritus será el agua, con un claro significado de renacer, el que dote de significado al emplazamiento de Sancti Spiritus por situarse en un lugar preeminente del territorio, con un amplio control del territorio, delimitado por dos de los principales cauces de agua de la región como son el río Carcarañá y coronda. El propio Luis Ramírez en su carta no deja lugar a dudas cuando dice que desde mayo de 1527 carecían de víveres traídos desde España y que cuando llegaron al asiento de Sancti Spiritus “...que con benir todos o los mas enfermos y ynchados de dibersas maneras de enfermedades con tener dieta con pescado y agua asta artar en menos de dos meses que alli llegamos estabamos todos tan buenos y tan frescos como quando salimos de spana..." (Maura, 2007. El subrayado y negrita es nuestro). Vemos, por tanto, cómo el pescado pero, sobre todo, el agua de esta zona adquiere un papel relevante, máxime cuando llevaban ya varios meses en la zona, enfermos, y nada habían señalado en relación al agua, y pescado.

Finalmente, el aspecto más importante al que nos hemos referido es el de la toma de posesión del territorio, ya que en Sancti Spiritus no creemos que se realizara ningún tipo de acto de fundación. Las tomas de posesión, por lo general, se efectúan nada más llegar al lugar y desembarcar en el mismo, ya que es la manera de legitimar el poder real sobre el territorio. Si bien la expedición de Sebastián Gaboto tenía un fin meramente mercantil, no es menos cierto que una de las clausulas contenidas en la capitulación firmada le permitía hacer hasta tres expediciones comerciales posteriores en las zonas nuevas descubiertas, ya fueran islas o tierra firme (Maura, 1908a). Por lo que el acto de posesión debió de acometerse con inmediatez a la llegada a la zona y no mucho tiempo después, máxime cuando el asentamiento de 


\section{Si Dionisio lo dice, o no? Sancti Spiritus y el acto de toma de posesión del territorio}

Sancti Spiritus se construyó directamente sobre un asentamiento originario existente (Letieri et al., 2015b).

No tenemos muchas dudas de que los datos que aporta la documentación escrita, para el caso que nos ocupa, son relevantes ya que nos permiten señalar que el trayecto desde San Salvador hasta Sancti Spiritus se realizaba en 6 o 7 días. Este dato nos permite proponer una fecha para el arribo a la confluencia de los ríos Carcarañá y Coronda situada entre el 14 y 15 de mayo de 1527. Sin embargo, el dato ofrecido por el cálculo del día de Pentecostés nos remite al 9 de junio de 1527, lo que sitúa esta data 25 o 26 días después de la elaborada a partir de la documentación escrita. En este sentido, apoyándonos en lo expuesto para la expedición de Juan Díaz de Solís o, para la posterior de Pedro de Mendoza (Groussac, 1912), la toma de posesión de los territorios se acometía en el momento mismo de llegar a los nuevos territorios, por lo que no transcurría excesivo tiempo entre la llegada y la toma de posesión, otro caso era ya la posterior fundación. En este sentido pensamos que entre la data extrapolable a partir de la documentación escrita y la celebración de Pentecostés en 1527 existen demasiados días de diferencia. Por lo que creemos, y así lo proponemos como hipótesis, más fundamentado el día 14/15 de mayo de 1527 para el asiento de Sancti Spiritus que el 9 de junio.

\section{Conclusiones}

En las páginas anteriores hemos tratado de hacer una revisión lo más rigurosa posible de los datos expuestos hasta la fecha relativos a la data de construcción de Sancti Spiritus. Como hemos visto, los principales autores que tratan la materia Madero, Medina y Groussac, sin olvidar la gran labor desarrollada por Amadeo P. Soler y más recientemente por Ricardo N. González, planteaban que la fecha de construcción de Sancti Spiritus era el 27 de mayo, 19 de mayo o 9 de junio respectivamente. Sólo Rubio supuso una data distinta, el 11 de mayo. Desconocemos en qué basaron sus propuestas o cómo realizaron los cálculos, a pesar de conocer que la fiesta de Pentecostés, como hemos señalado, se trataba de una celebración movible. Sea como fuere, resultó que finalmente se institucionalizó la fecha del 9 de junio que, como hemos apuntado, ha sido la más repetida desde comienzos del siglo XX. Es curioso constatar cómo en el momento de declarar el Fuerte Sancti Spiritus, primera fundación española en la comarca del Río de la Plata, como lugar histórico en 1942 no se señala nada en relación a su fecha de fundación, por lo que la idea generalizada de que la fundación fue el 9 de junio de 1527 tiene que ser, necesariamente, de un momento posterior.

Sea como fuere, esta indefinición histórica, ha tenido su repercusión en alguno de los actos de conmemoración actual. Así, tal y como relata Mario Alfredo Lacava en el prólogo al libro de Ricardo N. González (2014), fue idea suya cuando ocupaba la Secretaria de Municipios y Comunas de la Provincia de Santa Fe, proponerle en 1998 al gobernador Jorge Alberto Obeid que decretara el día 9 de junio Día de los Municipios en recuerdo a la fundación de Sancti Spiritus. Así fue como el 3 de junio 
de 1998 se suscribió el Decreto № 1169 mediante el cual se establece, entre otras celebraciones, que el 9 de junio se conmemore el Día de los Municipios, Comunas y Pueblos de la provincia en conmemoración de la fundación del asentamiento de Sancti Spiritus (Lacava en González, 2014).

Con el presente trabajo hemos pretendido ofrecer algo de luz sobre un aspecto no debidamente tratado por la historiografía, pero que aún estamos a tiempo de revertir ante la inminente llegada del 500 aniversario de la construcción del asentamiento de Sancti Spiritus. Si bien los datos que hemos expuesto no son todo lo concluyentes que debieran, e incluso son contradictorios entre sí, pensamos que la revisión documental que hemos efectuado, así como la propuesta de los diferentes matices simbólicos que adquiere el Espíritu Santo, es más que significativo para proponer una nueva data del arribo de los expedicionarios a la confluencia de los ríos Carcarañá con el Coronda y la toma de posesión del territorio donde se emplazó el asentamiento de Sancti Spiritus. Por ello, creemos que la fecha derivada del análisis documental de 14/15 de mayo de 1527 se ajusta más a los datos conocidos para definir el día del arribo de los expedicionarios y la toma de posesión del territorio en el que se construyó el asentamiento.

\section{Agradecimientos}

A nuestros compañeros, pasados y presentes, del proyecto "Localización del primer asentamiento español en el Río de la Plata", a quienes apoyan este proyecto: Ministerio de Cultura (España) a través de las ayudas para proyectos arqueológicos en el exterior; al Ministerio de Cultura de la Provincia de Santa Fe. A los estudiantes de la carrera de Antropología de la UNR que han participado en el Proyecto. A la Comuna y comunidad e instituciones educativas de Puerto Gaboto, y en especial a Juan Pablo Merani por su colaboración desinteresado. La redacción final de este trabajo por parte de Iban Sánchez Pinto ha sido posible gracias a la beca obtenida en la convocatoria 2018 de ayudas para la Especialización de Personal Investigador del Vicerrectorado de Investigación de la UPV/EHU.

\section{Bibliografía}

AGI/22.15.2582//INDIFERENTE, 2495, L.1

Amarilla Fretes, E. (1942) Asunción, Ciudad madre de ciudades (la fundación de Buenos Aires). Asunción: Imprenta Nacional.

Arber, E., (Ed.). (1885) The first three english books on America 1511-1555. Being chiefly translations, complilations \&c, by Richard Eden. Birmingham: 1 Montague Road. 


\section{Si Dionisio lo dice, o no? Sancti Spiritus y el acto de toma de posesión del territorio}

Astiz, M. E. (2013) La expedición de Sebastián Caboto a las Molucas y el fuerte Sancti Spiritus (1527-1529). Revista de la Junta Provinvial de Estudios Históricos de Santa $\mathrm{Fe}, 70,101-135$.

Astiz, M. E., \& Tomé, A. (1987) Localización y descripción de Sancti Spiritus (15271529). Cuadernos Instituto Nacional de Antropología, 12, 203-251.

Azara, F. De. (1847). Descripción e historia del Paraguay y del Rio de la Plata. Madrid: Imprenta de Sánchez.

Azkarate, A., \& Escribano-Ruiz, S. (2015) The Early Colonisation of the Rio de la Plata Basin and the Settlement of Sancti Spiritus. En P. P. Funari \& M. X. Senatore (eds.), Archaeology of Culture Contact and Colonialism in Spanish and Portuguese America (pp. 39-52). Cham: Springer. doi 10.1007/978-3-319-08069-7_3.

Azkarate, A., Escribano-Ruiz, S., Sánchez-Pinto, I. \& Benedet, V. (2018) Sancti Spiritus, 1527-1529. El primer intento colonizador del Cono Sur (Argentina). Anejos de NAILOS, 4, 71-88.

Azkarate, A., Escribano-Ruiz, S., Sánchez-Pinto, I., \& Benedet, V. (2016) Thoughts on Early Spanish Colonialism through two American case studies: Basque Fisheries (Canada) and Sancti Spiritus Settlement (Argentina). En S. Montón Subías, A. Ruiz \& M. C. Berrocal (Eds.), Archaeologies of Early Modern Spanish Colonialism (93-115). Cham: Springer. doi: 10.1007/978-3-319-21885-4_5.

Azkarate, A., Sanchez-Pinto, I., Escribano-Ruiz, S., \& Benedet, V. (2014) Aproximación al enredo cultural provocado por la presencia española temprana en la Cuenca del Plata; el caso del fuerte de Sancti Spiritus, 1527-1529. Revista de Arqueología Americana 32, 45-73.

Báez, J. R. (1944) La primera colonia agrohispana en el río de La Plata. Sancti Spiritus cuna de la agricultura platense. Revista argentina de agronomía 11, 278-286.

Benzi, M. (2013) La socialización en el proceso de investigación, el caso del fuerte Sancti Spiritus. Revista del Museo de La Plata, Sección Antropología, 13 (87), 429443.

Bonomo, N., Osella, A., Martinelli, P., de la Vega, M., Cocco, G., Letieri, F., \& Frittegotto, G. (2012) Location and characterization of the Sancti Spiritus Fort from geophysical investigations. Journal of Applied Geophysics 83: 57-64.

Butcher, S. (1877) The Ecclesiastical calendar: its theory and construction. Dublin: Hodges, Foster and Figgis. London: Macmillan \& co.

Calvo, L. Mà. (2003) La construcción de una ciudad hispanoamericana. Santa Fe la Vieja entre 1573-1660. Santa Fe: Universidad Nacional del Litoral. 
Calvo, L. Mạ (2017) Génesis y desarrollo de la ciudad iberoamericana. En P. A. Escalante Arce \& G. Herodier (dirs.). Génesis y desarrollo de la ciudad iberoamericana: actas del IV Seminario RII-UC. El Salvador: Editorial Universitaria. Universidad San Salvador (UES), pp. 157-175.

Canals Frau, S. (1948) La primera entrada al territorio argentino. Anales del Instituto Étnico Nacional. Tomo I: 17-35.

Candela, G. (2007/2008) Domingo Martínez de Irala, el protagonista de la historia de la conquista del Paraguay entre 1537 y 1556 (Mémoire Master I). Université de Provence, Centre d'Ais, UFR E.R.L.A.O.S, Département d'Etudes LatinoAmeéricaines.

Candela, G. M. (2014) El fuerte de Buenos Aires en 1541 entre despoblación y destrucción. En F. Vela Cossio (Coord.) Arqueología de los primeros asentamientos urbanos españoles en la América Central y Meridional: actas del I seminario internacional I RII_UC. Escuela Técnica Superior de Arquitectura de la Universidad Politécnica de Madrid, Madrid, pp. 289-300.

Capparelli, A., Lema, V., Giovannetti, M., \& Raffino, R. (2005) The introduction of Old World crops (wheat, barley and peach) in Andean Argentina during the 16th century A.D.: archaeobotanical and ethnohistorical evidence. Vegetation History and Archaeobotany, 14, 472-484.

Cappelli, A. (1930) Cronologia, Cronografia e Calendario Perpetuo. Milán: Ulrico Hoepli editore.

Castañeda, P., Cuesta, M., \& Hernández, P. (1983) Transcripción, estudio y notas del Espejo de navegantes de Alonso de Chaves (1520-1538). Madrid: Instituto de Historia y Cultura Naval.

Castaño Fernández, A. Mํ. (1998) Los nombres de La Serena. Mérida: Editorial Regional de Extremadura.

Cervera, M. M. (1908) Historia de la ciudad y provincia de Santa Fe 1573-1853. 3 vols. Santa Fe: Librería imprenta y encuadernación “La Unión” de Ramón Ibáñez.

Cocco, G., \& Letieri, F. (2009) Proyecto: localización del primer asentamiento español en la Cuenca del Río de la Plata - Fuerte Sancti Spiritus 1527-1529 localidad de Puerto Gaboto Pcia. de Santa Fe. En M. A. Berón, L. H. Luna \& M. Bonomo (Eds.), Mamül mapu: pasado y presente desde la arqueología pampeana, 2 (419-429). Buenos Aires: Editorial Libros del Espinillo.

Cocco, G., Letieri, F., Frittegotto, G., Pasquali, C., Azkarate, A., Sánchez-Pinto, I., Escribano-Ruiz, S., \& Benedet, V. (2016) Sancti Spiritus, 1527-1529. Aportes al 


\section{Si Dionisio lo dice, o no? Sancti Spiritus y el acto de toma de posesión del territorio}

estudio de los primeros asentamientos europeos en Sudamérica. En L. M. Calvo \& G. Cocco (Comp), Primeros asentamientos españoles y portugueses en la América central y meridional: siglos XVI y XVII (201-220). Colección Ciencia y Tecnología. Santa Fe: Ediciones UNL.

Colobig, Ma de los M., Zucol, A. F., Passeggi, E., Azkarate, A., \& Sánchez-Pinto, I. (2019) El sitio Fuerte Sancti Spiritus (1527-1529), Puerto Gaboto, Santa Fe, Argentina. Una aproximación a partir del análisis de microrrestos biosilíceos. En L. Salvatelli \& M. Roca \& M.A. Schmitz (coomp.), Libro de resúmenes. VIII Encuentro de Discusión Arqueológica del Nordeste (p. 20). Posadas: Universidad Nacional de Posadas.

Colobig, Ma de los M., Zucol, A., Brea, M., Franco, M. J., Passeggi, E., Cocco, G., \& Sánchez-Pinto, I. (2017) Restos arqueobotánicos del sitio arqueológico Fuerte Sancti Spiritus, Santa Fe, Argentina. COMECHINGONIA. Revista de Arqueología, 21 (2), 275 304.

Cuesta Domingo, M. (1983) Alonso de Santa Cruz y su obra cosmográfica. Madrid: CSIC.

Cuesta Domingo, M. (2016) Antonio de Herrera y su Historia General del Mundo, 4 vol. Madrid: Boletín oficial del Estado BOE, Colección Derecho Histórico.

Díaz, E. N. (2000) Estudio cartográfico e histórico del viaje de Pedro Sarmiento de Gamboa (1579-1580). En XIII Coloquio de Historia Canario-Americana; VIII Congreso Internacional de Historia de America (AEA) (1998) (898-912). Cabildo Insular de Gran Canaria.

Domínguez Company, F. (1977) Actas de fundaciones de ciudades Hispanoamericanas. Revista de Historia de América, 83: 19-51.

Echániz Sans, M. (1992) La puebla de Sancti Spiritus de Salamanca. Un señorío de la Orden de Santiago en el siglo XIII. En J. L. Martín Rodríguez (Coord.), Actas del I Congreso de Historia de Salamanca (432-437). Salamanca: Diputación de Salamanca.

Echániz Sans, M. (1993) Sancti Spiritus de Salamanca. Salamanca: Universidad de Salamanca.

El Jaber, L. (2011) Un país malsano. La conquista del espacio en las crónicas del Río de la Plata (siglos XVI y XVII). Rosario: Beatriz Viterbo Editora; UNR.

Espíritu Santo. (2020) Recuperado de https://www.significados.com/espiritusanto/ consulta de 27/08/2020.

Estornés Zubizarreta, I. (2020) Universidad de Oñati. Historia. Auñamendi Entziklopedia. Recuperado de http://aunamendi.eusko- 


\section{Iban Sánchez-Pinto y Gabriel Cocco}

ikaskuntza.eus/eu/universidad-de-onati-historia/ar-129273/ consulta de 25/08/2020.

Fernández de Oviedo, G. (1959) Historia General y Natural de las Indias, vol. V. J. Pérez de Tudela (ed.) Biblioteca de Autores Españoles, vols. CXVII-CXXI. Madrid: Atlas.

Florstedt, R. (1942) Diego Velázquez, first governor of Cuba. Thesis Presented for the Degree of Master of Arts. Ohio: Ohio State University. Recuperado de $\underline{\text { http://rave.ohiolink.edu/etdc/view?acc num }=0 \text { su1184951843 }}$ consulta de $27 / 08 / 2020$.

Frittegotto G., Letieri F., Cocco G., Pasquali C., Astiz, M. E., \& Valdata M. (2013) Descubriendo el Fuerte Sancti Spiritus. Colección Estudios y proyectos Especiales. Buenos Aires: Consejo Federal de Inversiones.

Gandía, E. (1929) Historia crítica de los mitos de la conquista americana. Buenos Aires: editores Juan Roldán y Compañía.

Gandía, E. (1932) Historia de la conquista del río de La Plata y del Paraguay 15351556, Buenos Aires: Librería de A. García Santos.

Gandía, E. (1934) El primer clérigo y el primer obispo del río de la Plata. Buenos Aires: editorial García Santos.

García Avilés, A. (2001) El tiempo y los astros. Murcia: Universidad de Murcia, Servicio de Publicaciones.

Gómez Pallarés, J. (1999) Studia Cronologica. Estudios sobre manuscritos latinos de cómputo. Madrid: Ediciones Clásicas.

González, J. (1943) Repoblación de la Extremadura leonesa. Hispania, 3: 195-273.

González, R. N. (2014). Puerto Gaboto. Génesis y desarrollo social del primer pueblo argentino. Rosario: auto edición.

Groussac, P. (1916). Mendoza y Garay. Las dos fundaciones de Buenos Aires 15361580. Buenos Aires: Jesús Menéndez, ed.

Gutiérrez, R., (1983) Arquitectura y Urbanismo en Iberoamérica. Madrid: Ediciones Cátedra.

Harrisse, H. (1896). John Cabot the discover of North-America and Sebastian his son. A chapter of the maritime history of England under the Tudors 1496-1557. London: Benjamin Franklin Stevens.

Jones, C. W. (1943): Bedae. Opera de temporibus. Cambridge: Mass. 


\section{Si Dionisio lo dice, o no? Sancti Spiritus y el acto de toma de posesión del territorio}

Lacava, M. A. (2014) Prólogo. En R. N. González, Puerto Gaboto. Génesis y desarrollo social del primer pueblo argentino. Rosario: auto edición.

Lafuente Machaín, R. (1936) Don Pedro de Mendoza y el puerto de Buenos Aires. Buenos Aires: Imprenta Amorrotu.

Lafuente Machaín, R. (1939) El gobernador Domingo Martínez de Irala. Buenos Aires: Librería y Editorial "La Facultad” Bernabé y Cia.

Lafuente Machaín, R. (2004) El fundador Juan de Salazar Espinosa. Asunción: Academia Paraguaya de la Historia, FONDEC.

Laguarda Trías, R. A. (1992) La carta más antigua en territorio uruguayo. Montevideo: Imprenta militar.

Ledesma Medina, Luis A. (1978) Conquistadores del Tucumán y la fortaleza de Gaboto en el siglo XVI. Junta Provincial de Estudios Históricos, 49, 389-393.

Letieri, F., \& Cocco, G. (2015) Cultura material y procesos interculturales en Sancti Spiritus (1527-1529). Un abordaje arqueológico contextual. Revista teoría y práctica de la arqueología histórica latinoamericana, Año IV, Vol. 4, 31-46.

Letieri, F., Escribano-Ruiz, S., Pasquali, C., Cocco, G., Azkarate Garai-Olaun, A., Sánchez-Pinto, I., \& De La Fuente, G. (2015a) Approaching the Cultural Complexity of Pottery from Sancti Spiritus Village and Fort (Puerto Gaboto, Argentina). En J. Buxeda \& M. Madrid \& J. G. Iñañez (eds.). Global Pottery 1. Historical Archaeology and Archaeometry for Societies in Contact. Oxford: BAR International Series, pp. 205-221.

Letieri, F., Cocco, G., Frittegotto, G., \& Sánchez-Pinto, I. (2015b) El Fuerte Sancti Spiritus. El primer asentamiento europeo en el actual territorio argentino. Revista Ciencia Hoy. Revista de Divulgación Científica y Tecnológica de la Asociación Civil CIENCIA HOY: 13-18.

Lorenzo, E. (1985) Castilla y León en América. Descubridores, conquistadores y colonizadores. Valladolid: Ámbito ediciones, S.A.

Lozano, P. (1875). Historia de la conquista del Paraguay, Río de la Plata y Tucumán. Buenos Aires: Imprenta Popular.

Madero, E. (1892) Historia del puerto de Buenos Aires. Buenos Aires: Imprenta de «La Nación», San Martín 344.

Maura, J. F. (2007) Luis Ramírez, Carta de Luis Ramírez a su padre desde el Brasil (1528): orígenes de los 'real maravilloso' en el Cono Sur. Col. Textos de la revista Lemir 2007. Recuperado de http://parnaseo.uv.es/Lemir/Textos/Ramirez.pdf consulta de 10/01/2020. 
Medina, J. T. (1897) Juan Díaz de Solís. Estudio Histórico. Santiago de Chile: Impreso en casa del autor.

Medina, J. T. (1908a) El veneciano Sebastián Caboto al servicio de España y especialmente de su proyectado viaje á las Molucas por el estrecho de Magallanes y al reconocimiento de la costa del continente hasta la gobernación de Pedrarias Dávila, Tomos I y II. Santiago de Chile: Imprenta y Encuadernación Universitaria.

Medina, J. T. (1908b) Los viajes de Diego García de Moguer. Santiago de Chile: Imprenta Elzeviriana.

Michieli, C. T. (1996) La fundación de las ciudades de Cuyo. San Juan: Ansilta Ed.

Mínguez, J. Ma․ (Coord.) (1997) Historia de Salamanca. Salamanca: Centro de Estudio Salmantinos.

Mora Aliseda, J. (Dir.) (2001) Extremadura Fin de siglo: Estudio de sus 388 municipios. Tomos I y II. Badajoz: Diario Hoy/Caja Duero.

Morales, M. A. (2017) Las matemáticas de la fecha del Domingo de Resurrección. El país, 13 de abril de 2017, Recuperado de https://elpais.com/elpais/2017/04/12/el aleph/1492008750 544261.html consulta de 01/02/2020.

Moreno Blanco, R. (2016) Aportaciones a la arquitectura y la historia del monasterio de Sancti Spiritus de Ávila. Espacio, Tiempo y Forma, Serie VII Historia del Arte, 395416.

Outes, F. F. (1902) El primer asentamiento español en territorio argentino (15271529). Noticia histórico-geográfica. Anales de la Sociedad Científica Argentina, LIV, 113-137. Buenos Aires: Imprenta y Casa editora de Coni hermanos.

Palacios, E. (2018) Mendoza la ciudad perdida. Buenos Aires: Editorial De los Cuatro Vientos.

Pasquali, C. (2012) Mayólicas y contenedores comerciales en el fuerte Sancti Spiritus (1527-1529). Revista AMÉRICA, no 21, 121-140.

Pasquali, C., \& Escribano-Ruiz, S. (2013) Mayólicas en el Fuerte Sancti Spiritus (1527-1529). Propuesta analítica y resultados provisionales. Revista del Museo de La Plata, Sección Antropología 13 (87), 405-416.

Pérez Vidal, M. (2008) Sancti Spiritus de Toro: arquitectura y patronazgo femenino. Liño: Revista anual de historia del arte (14): 9-21. 


\section{Si Dionisio lo dice, o no? Sancti Spiritus y el acto de toma de posesión del territorio}

Plaza Picón, F. del M., \& González Marrero, J. A. (2005) Ciencias al servicio del cómputo. El De Temporibus Liber de Beda. Fortunatae 16, 217-224.

Prieto Benavent, J. L. (2001) Diego Velázquez de Cuellar (1465-1524). Fundador de Asunción de Baracoa, Santiago de Cuba, San Salvador del Bayamo, Puerto Príncipe, Sancti Spiritus, Remedios y San Cristóbal de la Habana. Revista Hispano Cubana, 9: 89-97.

Rodríguez Matamoros, M. E. (2013) Arqueólogos cienfuegueros participan en investigaciones en el sitio fundacional de la villa de Sancti Spíritus. Cuba Arqueológica, año VI, 1, 61-62.

Rosa, J. M. (1970) Historia Argentina. Vol I. Buenos Aires: Ed. Oriente.

Rubio, J. M. (1942) Exploración y conquista del Río de la Plata. Siglos XVI y XVII. Barcelona: Imprenta Hispano Americana, S.A.

Saint-Lu, A. (1986) Bartolomé de Las Casas. Historia de las Indias. Caracas: Biblioteca Ayacucho. Colección Clásicos.

Schavelzon, D. (1999) Arqueología de Buenos Aires. Buenos Aires: Emecé.

Schavelzon, D. (2001) Catálogo de Cerámicas Históricas de Buenos Aires (Siglos XVIXX). Con notas sobre la región del Río de la Plata. Version en PDF. Buenos Aires.

Schavelzon, D. (2012) Arqueología de la primera Buenos Aires (1536-1541). Entre la historia y el mito. http://www.iaa.fadu.uba.ar/cau/?p=3174 consulta de 3 de agosto de 2020.

Soler, A. P. (1981) Los 823 días del Fuerte Sancti Spiritus y la vigencia permanente de Puerto Gaboto. Rosario: Amalevi.

Soler, A. P. (1984) Sebastián Gaboto el primer argentino. Rosario: Amalevi.

Soler, A. P. (1987) La torre de Gaboto. Rosario: Amalevi.

Taylor, E. G. R. (Ed). (1932) A brief summe of geographie by Roger Barlow. London: Printed for the Hakuyt society.

Teres, G. (1984) Time computations and Dionysius Exiguus. Journal for the History of Astronomy 15, 177-188.

Thurston, H. (1909) "Easter Controversy." The Catholic Encyclopedia. Vol. 5. New York: Robert Appleton Company. 


\section{Iban Sánchez-Pinto y Gabriel Cocco}

Tieffemberg, S. (2012) Argentina: historia del descubrimiento y conquista del Río de la Plata de Ruy Díaz de Guzmán. Buenos Aires: Editorial de la Facultad de Filosofía y Letras Universidad de Buenos Aires.

Vargas Machuca, B. de. (1599) Milicia y descripción de las Indias por el Capitán don

Bernardo de Vargas Machuca. Recuperado de http://www.cervantesvirtual.com/obra/milicia-y-descripcion-de-las-indias consulta de $27 / 08 / 2020$.

Villar y Macías, M. (1887) Historia de Salamanca. T. I, II, II. Salamanca: Imprenta de Francisco Núñez Izquierdo.

Wright, I. A. (1916) The early history of Cuba. New York: The Macmillan Company.

Recibido: 09/03/2020

Evaluado: 05/05/2020

Versión Final: 30/07/2020 